\title{
白垔系钻质超微化石的发现一一在辽河 盆地中它们与渐新统超微化石混存
}

\author{
钟篗春费轩冬 \\ (石油勘探开发科学研究院, 北京)
}

随着我国东部地区下第三系古生物化石中某些海相属种的相继发现, 许多学者都认识到 我国东部下第三系沉积时期, 沉积盆地与海水有过联系或不止一次地遭受过短暂的海侵. 笔 者近几年来对辽河盆地和东兴盆地(华北)等下第三系渐新统沙河街组沙一段中钙质超微化石 的研究,为上述海浸问题补充了新的材料.

在本文中笔者想提出一项引人注意的资料, 这就是我们在研究辽河盆地兴 253 井早第三 系的超微化石时, 发现了确属白严系的几个属种。

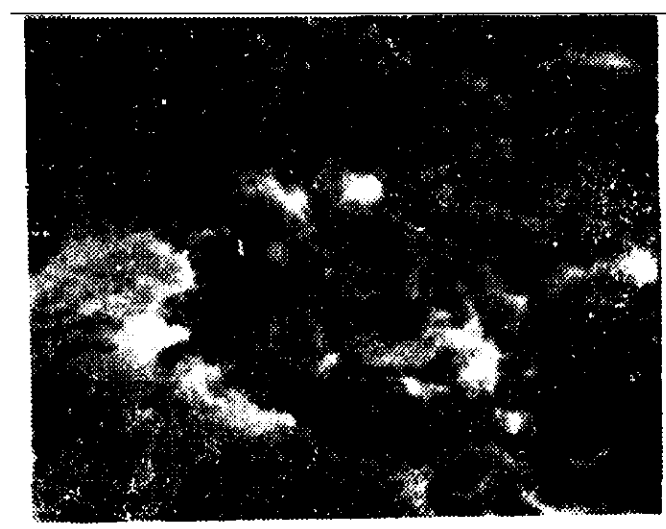

图 1 超微化石概貌. 电镜扫描 $(\times 3200)$

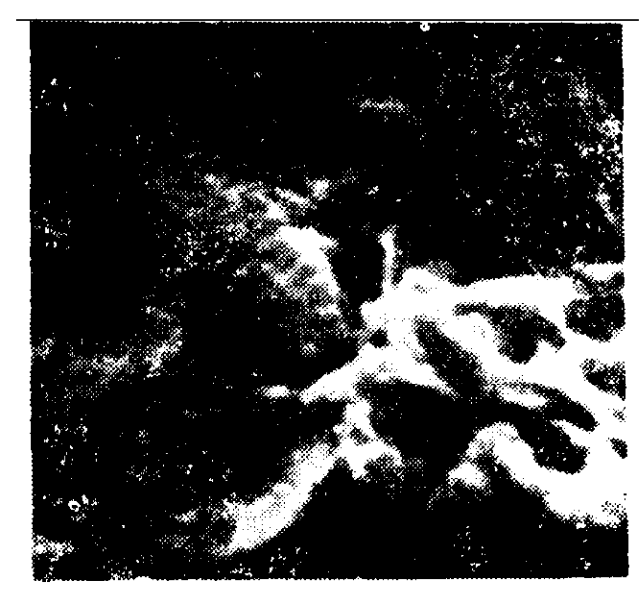

图 3 Reticulofenestra sp. 电镜扫描 $(\times 6600)$ 上、下近端视,中远端视

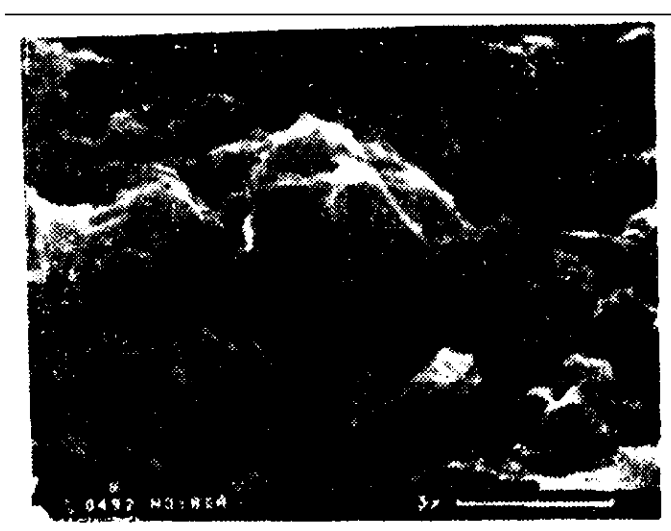

图 2 超微化石概貌. 电镜扫描

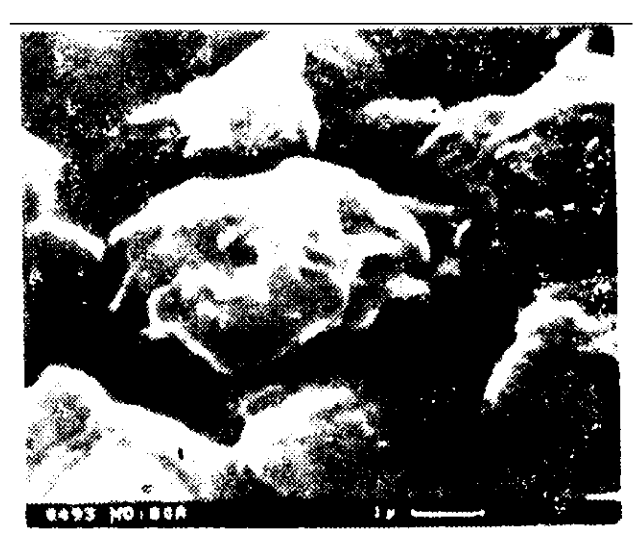

图 4 Cyclococcolithina sp., 远端视。 电镜打描

本文 1984 年 8 月 2 日收到. 
辽河盆地兴 253 井位于辽河西部拗陷的兴隆台构造上, 该构造为辽河盆地的主要油田之 一. 渐新统沙一段下共有五个油层组, 除第三油层组外, 其它油组均有岩心, 取心井段为 1702-1739 米、1784-1883 米. 油层组的岩性一般为砂砾岩或含砾砂岩、粉-细砂岩, 不含钻 或微含钻,而在第五油层组中部则有一套层理较发育的灰褐色钻片页岩, 裂隙中有油迹, 并见 黄铁矿脉充填. 油层组之间的地层, 其岩性主要为深灰色泥岩、浅灰色钻片页岩及含钻泥岩, 页理清楚，有的层位含丰富的介形虫及腹足类等化石．䥻质超微化石几乎见于整个剖面的䥻 片页岩或含钻的泥页岩中, 既使对第五油层组中部也不例外, 甚至在微含钻的油层组的夹层中 也能见到. 所见化石个体都很小,一般为 2 微米左右,经笔者鉴定有: Reticulofenestra sp. (见图 $1 、 2 、 3)$ Cyclococcolithina sp. (图 4) 等属 ${ }^{[1,2]}$. 沙河街组的地层时代经各门类古生物研究属渐 新统无疑. 钻质超微化石的发现目前对时代的进一步划分还提不出新的见解。这是由于所发 现的化石表现出属种单调,变异性大,难与标准的超微化石及其组合 (Martini, 1971) 相比 ${ }^{[3]}$. 因此, 许多问题还有待进一步研究. 引人注意的是, 钻质超微化石除上述第三系分子外, 在有 些层位中尚夹杂有白严系个体，并且有相当一部分层位则完全为白严系属种. 这些化石经鉴 定有: Phanulithus obscurus (Dflandre)Wind and Wise (见图 5)、Quadrum cf. gartneri Prins and

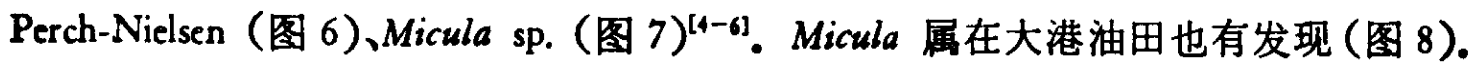

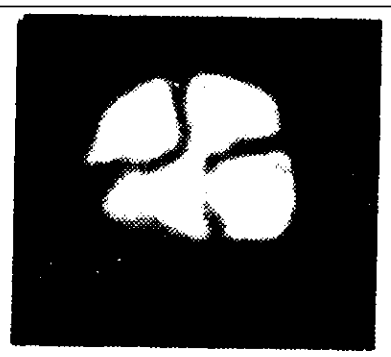

(5hanulithus obscurzs (Dflandre) Wind and Wise. 正交偏光 $(\times 5140)$

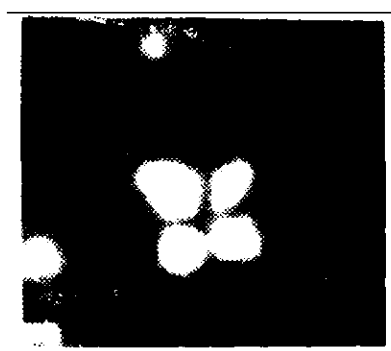

图 7 Micula sp. 正交偏光 $(\times 4320)$

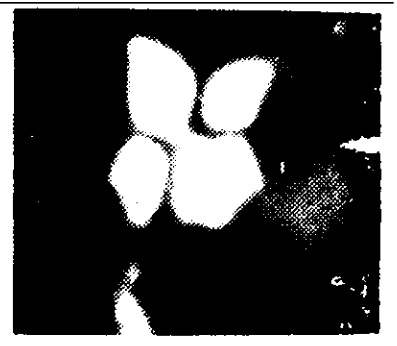

图 6 Q:tadrum cf. gartneri Prins and l'erch-Nielsen. 正交偏光 $(\times 4610)$

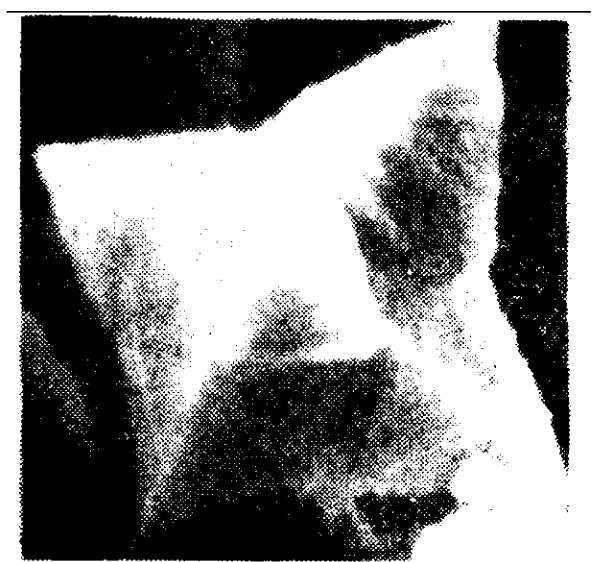

图。 Micula concava (stradner) Bukry. 电镜扫描, 顶视 ( $\times 6300)$ (由陈丽华提供)

关于我国东部含油气盆地中的白严纪地层, 除松辽、二连盆地外,其它地区研究极少,整个 渤海湾地区更末曾有过关于海相化石发现的报道. 所以兴 253 井第三系中白严纪超微化石的 发现, 不能不使我们慎重对待. 为此, 我们将所发现的部分化石资料请国外经验丰富的专家 Carla Müller 博士(德)及 A. R. Lord 博士(英)作了复核, 他们都证实了我们的鉴定是正确的, 
并指出这些属种仅限于白严纪，绝无延伸到第三纪的可能. 同时, 还为我们提供了有关资料。 辽河盆地发现的这些白严系钻质超微化石属于一些抗溶性强的属种, 因其个体小极易投运, 再 沉积保存下来, 从而出现在新的层系之中, 欧州西北部上白严统海相地层遭受剥蚀后, 常在新 的地层一一第三系和第四系中再沉积着大量的白严纪的钙质超微化石, 这是一个相当普遍的 现象. 这类再沉积的白严系属种有时甚至会多于本时代(新生代)原生的钙质超微化石. 这岕 正是我们在辽河盆地所见到的现象. 还值得提出的是, 第三系中含有白严系钻质超微化石的 情况, 在中原油田、苏北油田及大港油田也有所发现, 正在进一步研究之中. 这一发现的另一 重要意义在于:它不仅表明我国东部地区第四系和第三系盖层之下白严系的普遍存在,而且还 为这一广大地区白严系中存在有海相夹层或有过海浸的某种影响, 提供了重要线索. 现已查 明我国东部地区凡与海水有过联系或有海水浸进的近海湖泊相沉积往往有丰富的石油生成。 因此,当前的发现,也将有利于我国东部白严系油气资源的估价.

致谢：工作中扬时中同志提供样品, Carla Müller 博士给予了热情的帮助,在此一并致谢.

[1] Carla Müller, Initial Reports of the Deep Sea Drilling Project. XLVIII (1979), 589-639.

[ 2 ] Haq, B. U. and Boersma, A. (Eds), Introduction to Marine Micropaleontology, 1980, 79-108.

[ 3 ] Martini, E., Standard tertiary and quaternary calcareous nannoplankton zonation, Proceedings of the II Planktonic Conference, Roma, 1971, 739-785.

[ 4 ] Roth, P. H. and Bowdler, J. L., Micropaleontology, 25(1979), 272-280.

[5] Sherwood, Jr. W. W. and Frank, H. W., Initial Reports of the Deep Sea Drilling Project, XXXVI, 304, PI. 33, 34, 36.

[ 6] Lord, A. R. (Ed.), A Stratigraphic Index of Calcareous Nannofossils, 1982, 81-135. 